\title{
Engineering the In-Plane Structure of Metallic Phase \\ Molybdenum Disulfide via Co and O Dopants toward Efficient \\ Alkaline Hydrogen Evolution
}

Dengfeng $\mathrm{Cao}^{\dagger \#}, \mathrm{Ke} \mathrm{Ye}^{\dagger \#}$, Oyawale Adetunji Moses ${ }^{\dagger \#}$, Wenjie $\mathrm{Xu}^{\dagger}$, Daobin $\mathrm{Liu}^{+*}$, Pin Song ${ }^{\ddagger}$, Chuanqiang $\mathrm{Wu}^{\dagger}$, Changda $\mathrm{Wang}^{\dagger}$, Shiqing Ding ${ }^{\dagger}$, Shuangming $\mathrm{Chen}^{\dagger}$, Binghui Ge ${ }^{2, \S}$, Jun Jiang ${ }^{\dagger}$, Li Song $^{+*}$

${ }^{\dagger}$ National Synchrotron Radiation Laboratory, Hefei National Laboratory for Physical Sciences at the Microscale, CAS Center for Excellence in Nanoscience, iChEM (Collaborative Innovation Center of Chemistry for Energy Materials), School of Chemistry and Materials Science, University of Science and Technology of China, Hefei, Anhui 230026, China

${ }^{\text {F}}$ School of Materials Science \& Engineering, Nanyang Technological University, Singapore 639798, Singapore

${ }^{\gtrless}$ Institute of Physical Science and Information Technology, Anhui University, Hefei 230601, China

§Beijing National Laboratory for Condensed Matter Physics, Institute of Physics, Chinese Academy of Science, Beijing 100190, China

${ }^{\#}$ These authors contributed equally.

Corresponding authors: 1dbin@ustc.edu.cn; song2012@ustc.edu.cn 


\section{EXPERIMENTAL SECTION}

\section{Computational Methods and Details}

All the calculations were performed using the Vienna $a b$ initio simulation program (VASP). ${ }^{1,2}$ The DFT (Perdew, Burke, and Emzerhof (PBE) functional $+\mathrm{U}$ approach) was applied to the molybdenum and cobalt centers. ${ }^{3,4}$ Values of 2.4 and 5 $\mathrm{eV}$ were chosen for U-J parameter of Mo and Co, respectively. ${ }^{5}$ For all calculations, the plane-wave energy cutoff is set to $400 \mathrm{eV}$, and geometric structures were fully relaxed until energy and forces were converged to $10^{-5} \mathrm{eV}$ and $0.01 \mathrm{eV} \AA^{-1}$. Monkhorst-Pack k-point meshes are employed for the full relaxation of geometry structures. The atomic flake and its neighboring image are separated by a vacuum space that exceeds $15 \AA$. The van der Waals (vdW) interactions are based on the zero damping DFT-D3 method of Grimme. Calculations on HER free energy diagram were performed at the surface of monolayer structures.

The actual reaction mechanism in alkaline HER follows the following key steps:

$$
\begin{aligned}
& *+\mathrm{H}_{2} \mathrm{O}+e^{-} \rightarrow \mathrm{H}^{*}+\mathrm{OH}^{-}(\text {Volmer step }) \\
& 2 \mathrm{H}^{*} \rightarrow \mathrm{H}_{2} \uparrow+*(\text { Tafel step }) \\
& \mathrm{H}^{*}+\mathrm{H}_{2} \mathrm{O}+e^{-} \rightarrow *+\mathrm{OH}^{-}+\mathrm{H}_{2} \uparrow(\text { Heyrovsky step })
\end{aligned}
$$

where * stands for an active site on the catalytic surface. The free energies for step (1) and step (3) should be the same at HER equilibrium potential. Under this assumption, computations on the exact free energy of $\mathrm{OH}^{-}$in solutions could be avoided by using computational hydrogen electrode. ${ }^{6}$ The free energies for each step are calculated as equation:

$$
\Delta \mathrm{G}=\Delta \mathrm{E}+\Delta \mathrm{ZPE}-\mathrm{T} \Delta \mathrm{S}
$$

The $\Delta \mathrm{E}, \Delta \mathrm{ZPE}$ and $\Delta \mathrm{S}$ are the different energy, zero-point energy, and entropy of the reaction, respectively. The $\Delta \mathrm{E}$ is obtained from analyzing the DFT total energies. The $\Delta \mathrm{S}$ is the entropy difference between the adsorbed state ant the gas phase. The $\mathrm{T}$ is of room temperature $298.15 \mathrm{~K}$. The $\triangle \mathrm{ZPE}$ of adsorbed species were obtained from harmonic vibrational frequency calculations by equation: 


$$
\mathrm{ZPE}=\frac{1}{2} \sum h v_{i}
$$

where $h$ is the Planck constant, $v_{i}$ are the computed vibrational frequencies.

Only adsorbed species vibrational modes were calculated explicitly, while the functionalized 1T-MoS 2 and SWNT were fixed (assuming vibrations of the $1 \mathrm{~T}-\mathrm{MoS}_{2}$ and SWNT are negligible), as done in previous theoretical studies ${ }^{7-11}$. The entropies of adsorbed species were neglected. The entropies and vibrational frequencies of molecules in the gas phase were taken from the NIST database ${ }^{12}$. 


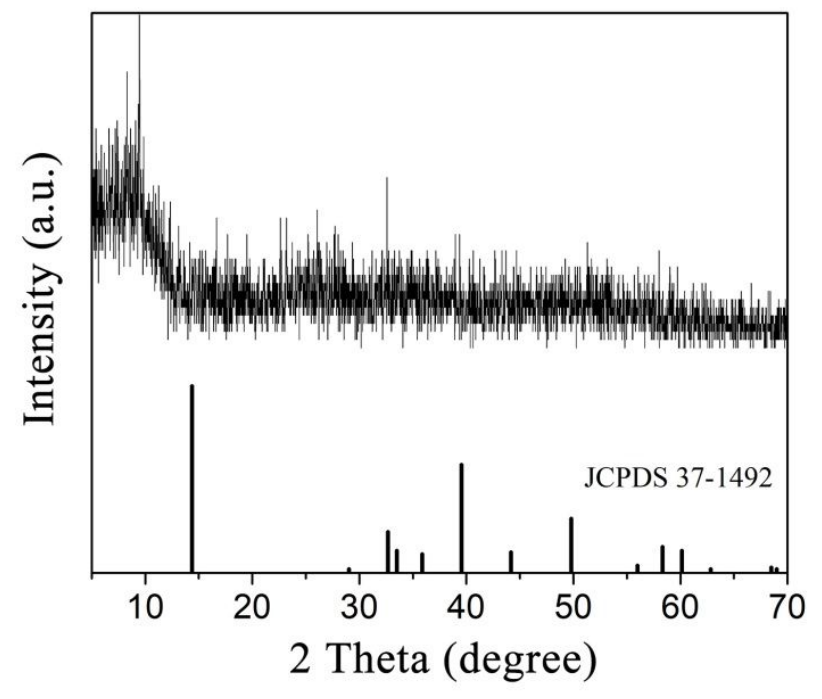

Figure S1. XRD pattern of as-prepared Co-O-1T-MoS $/ \mathrm{SWNT}$ hybrid, it shows the shift of (002) peak due to the intercalation of ammonium ions when compared with JCPDS card of $\mathrm{MoS}_{2}$. 

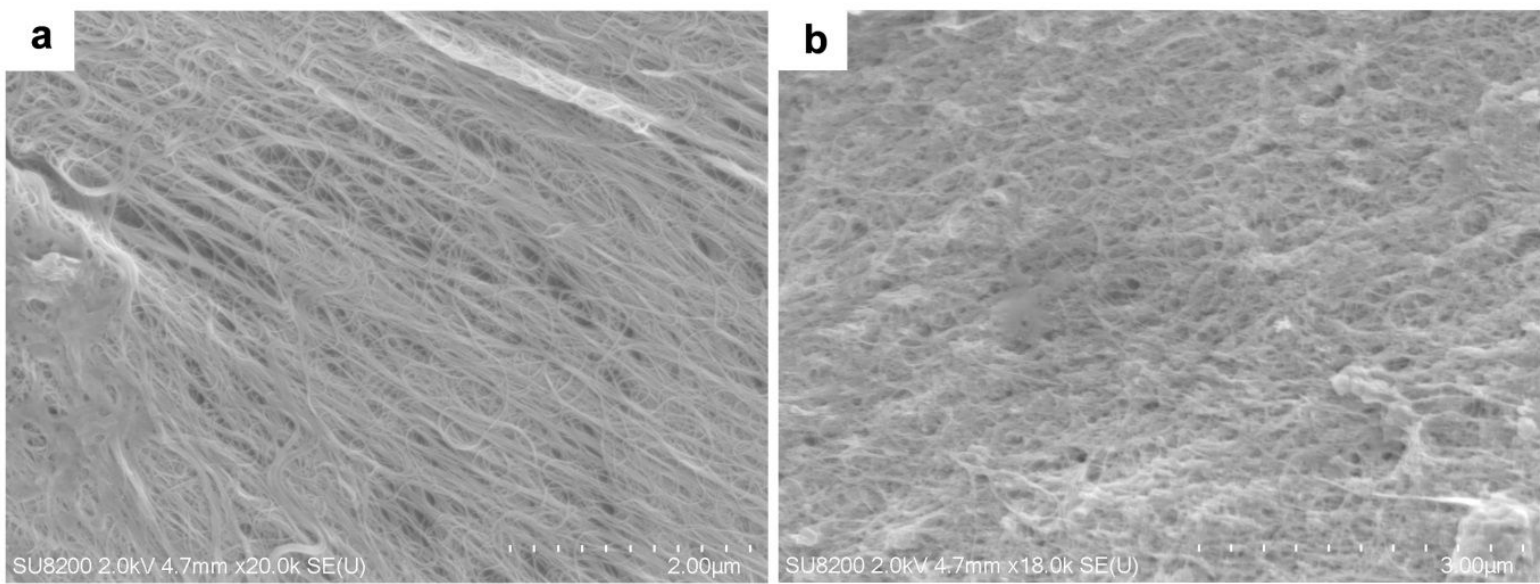

Figure S2. SEM images of (a) the bare SWNT film and (b) the Co-O-1T- $\mathrm{MoS}_{2} / \mathrm{SWNT}$ hybrid. 

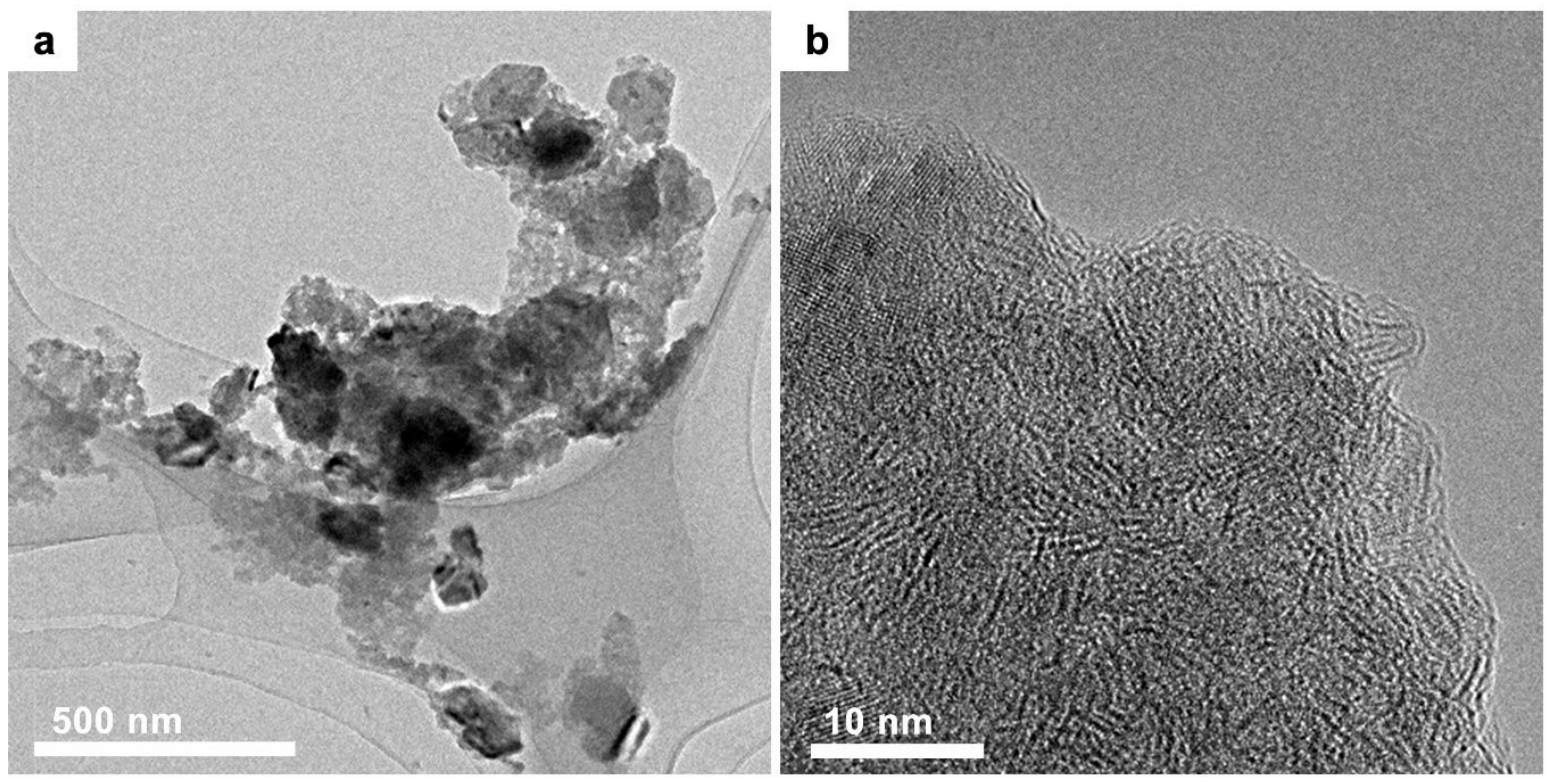

Figure S3. (a) TEM and (b) HRTEM images of Co-O-1T-MoS 2 aggregates, which was synthesized without the SWNT film in solvothermal process. 

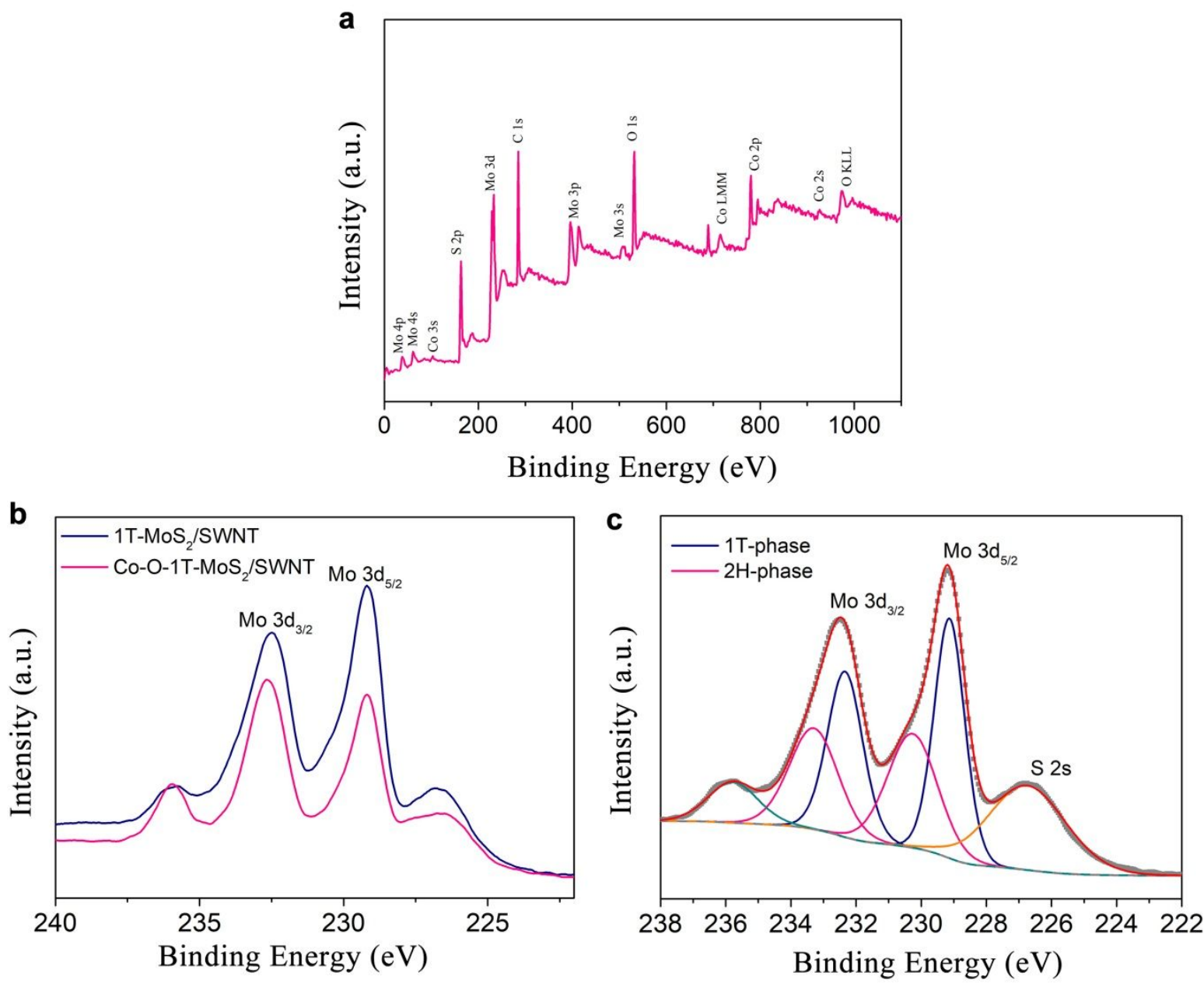

Figure S4. (a) XPS survey spectrum for Co-O-1T-MoS $2 / S W N T$. (b) Detailed Mo 3d XPS spectra of Co-O-1T-MoS $/$ SWNT and $1 \mathrm{~T}-\mathrm{MoS}_{2} / \mathrm{SWNT}$. (c) Deconvolution of Mo 3d XPS spectrum in 1T-MoS $2 /$ SWNT with the different components by Gaussian fitting. 


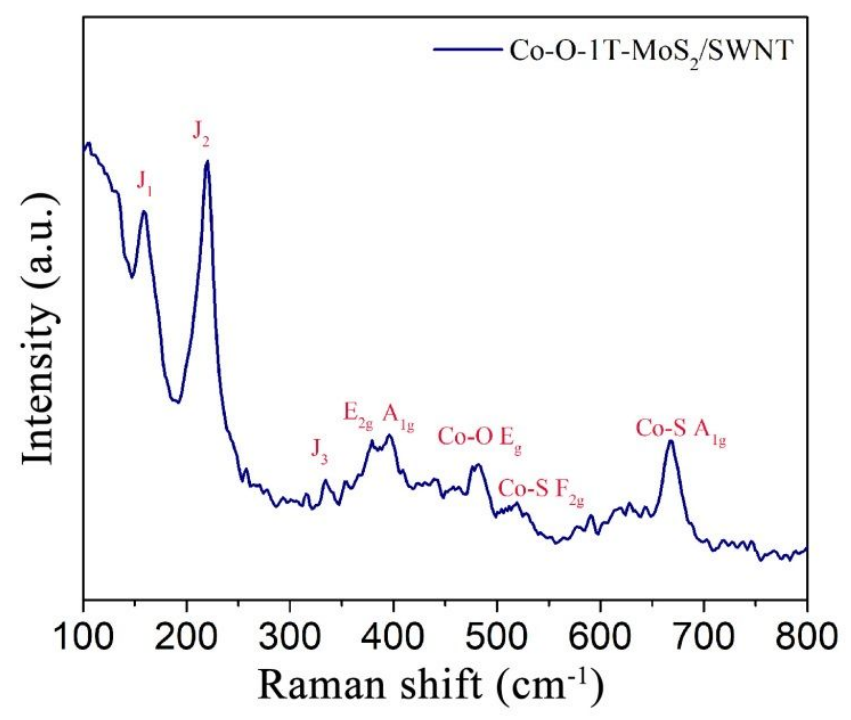

Figure S5. Raman spectra of Co-O-1T-MoS $/$ SWNT, which shows the characteristics of $1 \mathrm{~T}$ phase $\mathrm{MoS}_{2}, \mathrm{Co}-\mathrm{S}$ and $\mathrm{Co}-\mathrm{O}$ species. 

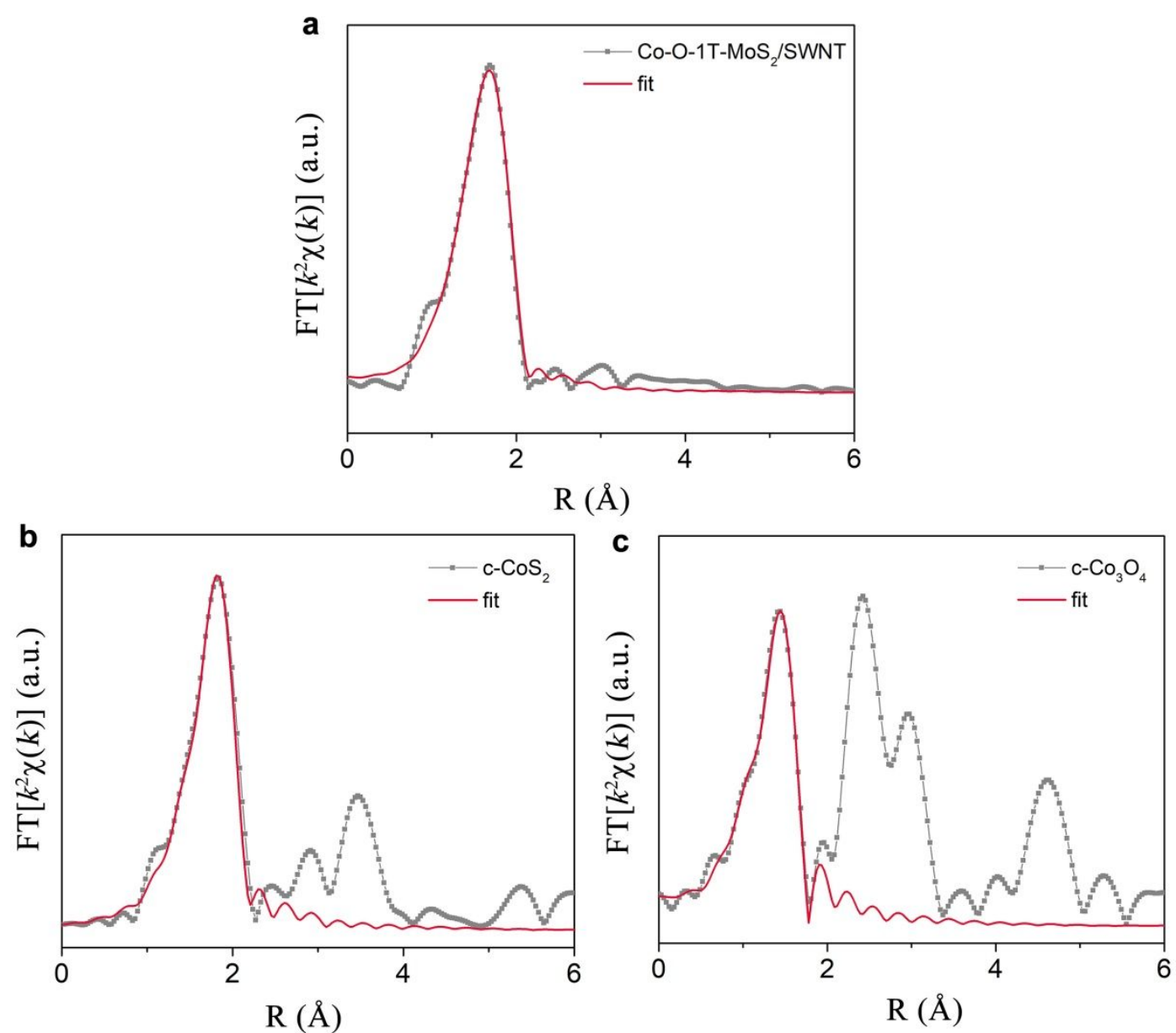

Figure S6. The Co K-edge EXAFS fitting curves of Co-O-1T- $\mathrm{MoS}_{2} / \mathrm{SWNT}$, along with c- $\mathrm{CoS}_{2}$ and $\mathrm{c}-\mathrm{Co}_{3} \mathrm{O}_{4}$ at $\mathrm{R}$ space. 


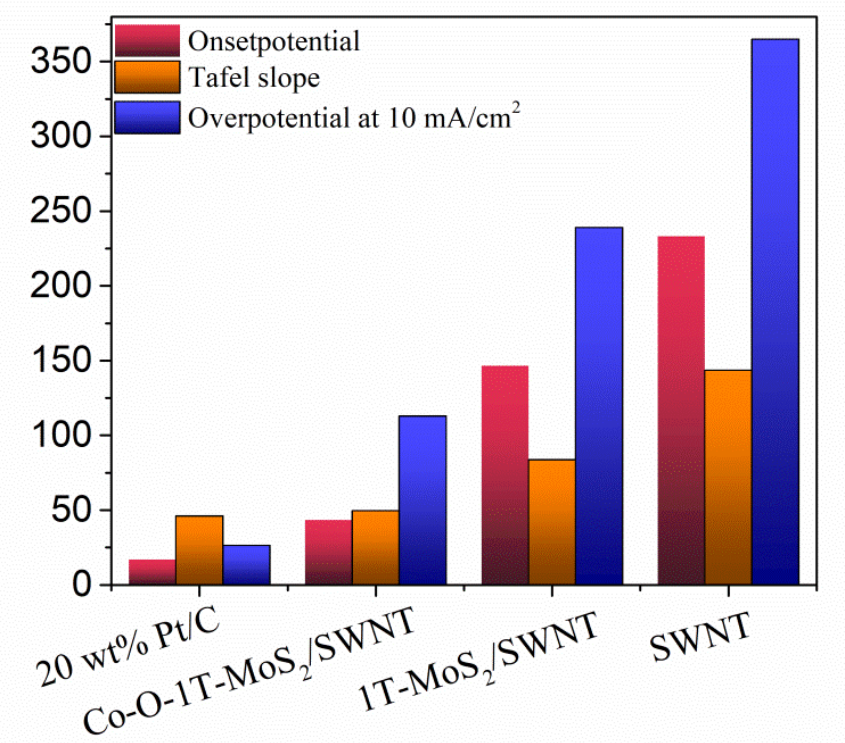

Figure S7. The onsetpotentials, overpotentials at $10 \mathrm{~mA} \mathrm{~cm} \mathrm{~cm}^{-2}$ and Tafel slopes of Co-O-1T- $\mathrm{MoS}_{2} / \mathrm{SWNT}, 1 \mathrm{~T}-\mathrm{MoS}_{2} / \mathrm{SWNT}, 20 \mathrm{wt} \% \mathrm{Pt} / \mathrm{C}$ and SWNT for hydrogen evolution in $1 \mathrm{M} \mathrm{KOH}$. 


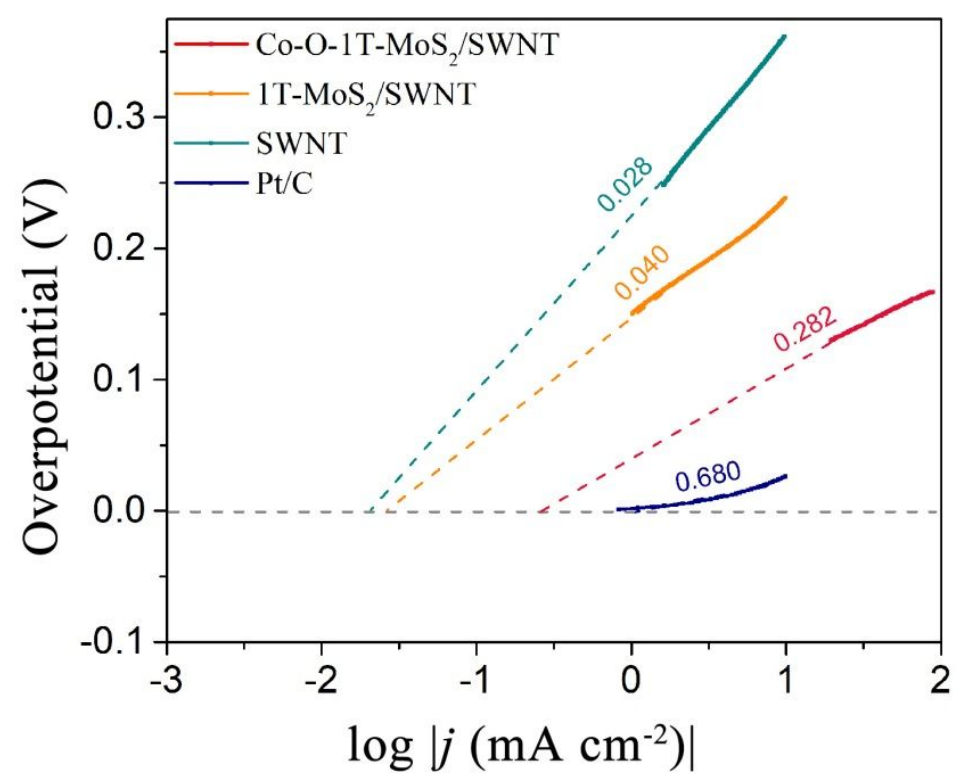

Figure S8. The exchange current density for all catalysts that derived from the tafel plot by an extrapolation method. 

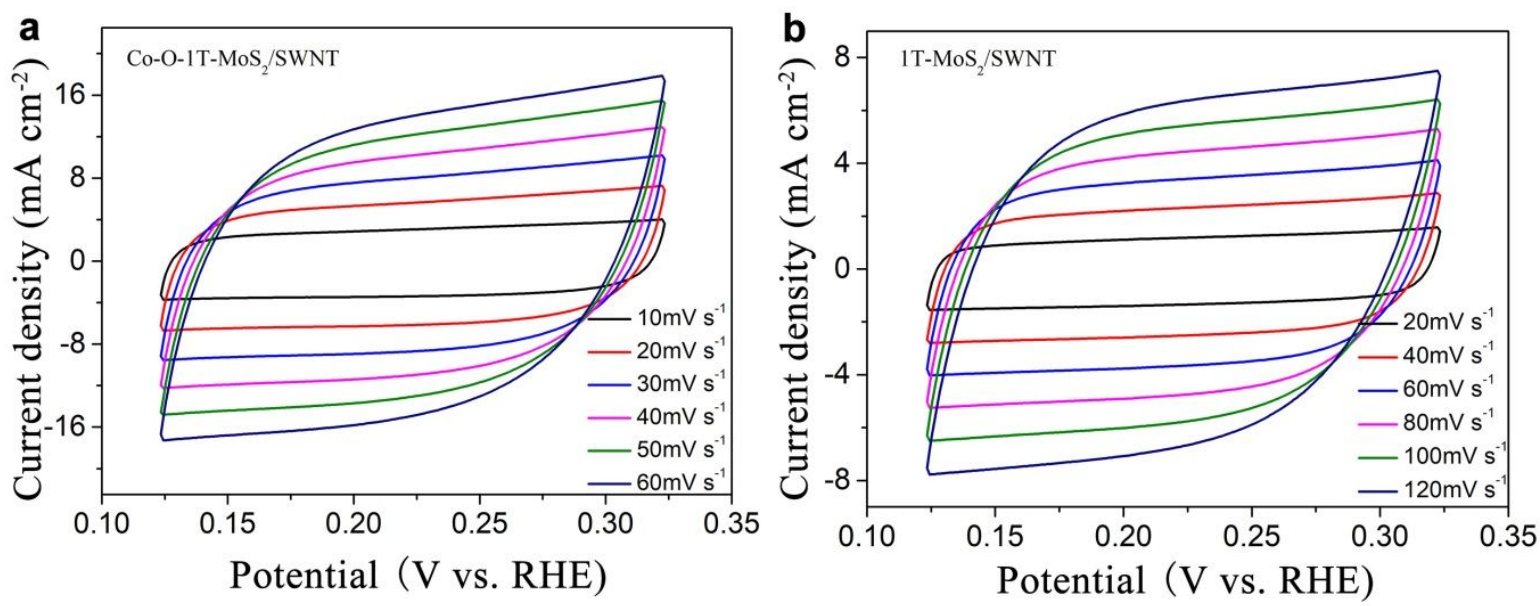

Figure S9. CV curves of Co-O-1T-MoS $2 / \mathrm{SWNT}$ and $1 \mathrm{~T}-\mathrm{MoS}_{2} / \mathrm{SWNT}$ in a range of $0.12 \sim 0.32 \mathrm{~V}$ ( vs. RHE) with non-faradaic reaction at different scan rate. 


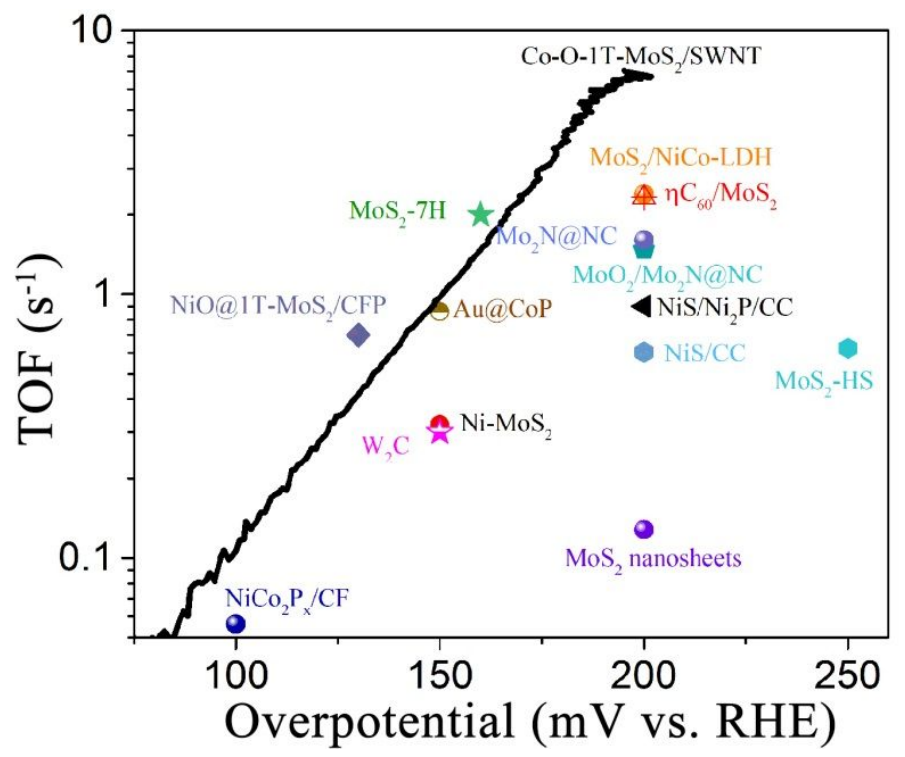

Figure S10. The turnover frequency (TOF) curve of Co-O- $1 \mathrm{~T}-\mathrm{MoS}_{2} / \mathrm{SWNT}$ in comparison with other previously reported catalysts. ${ }^{13-22}$ 


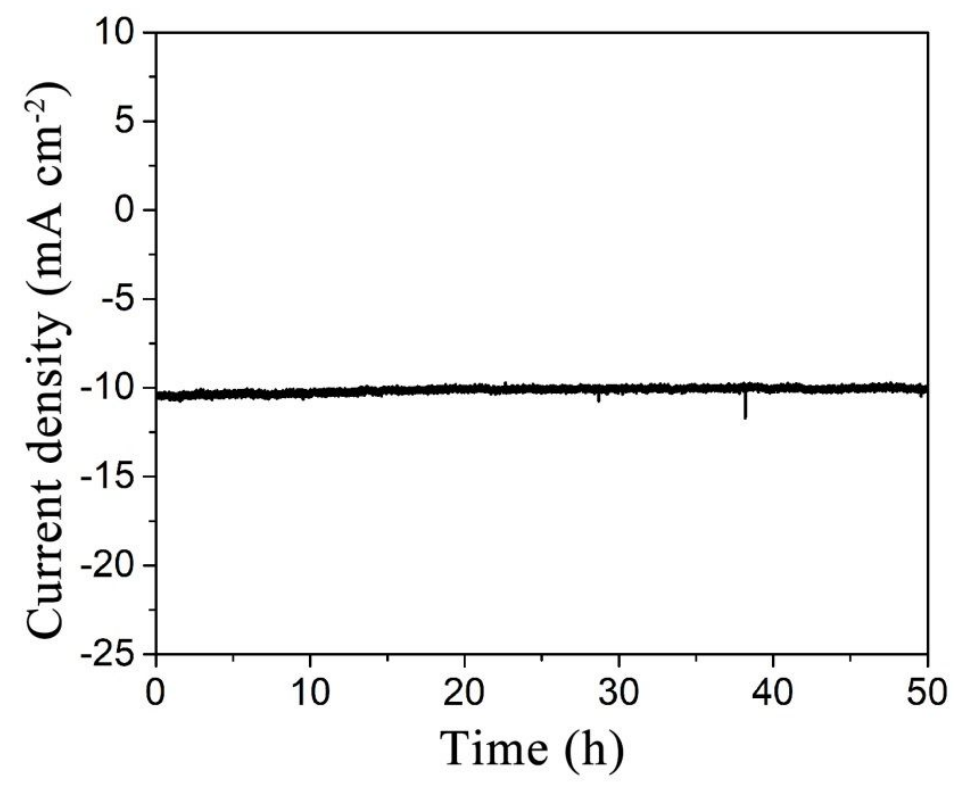

Figure S11. Time-dependent current density curve of Co-O-1T- $\mathrm{MoS}_{2} / \mathrm{SWNT}$ using $\mathrm{Hg} / \mathrm{HgO}$ electrode as the reference electrode.

Several concerns remain when used $\mathrm{Ag} / \mathrm{AgCl}$ electrode as the reference electrode in alkaline media: (1) the $\mathrm{Fe}$ and $\mathrm{KCl}$ contaminates may be leaching from the porous glass and the fill solution. (2) The $\mathrm{OH}^{-}$ions can permeate into the $\mathrm{KCl}$ filling solution, and then the reference electrode potential may shift slightly caused by the redox couple $\left(2 \mathrm{Ag}+2 \mathrm{OH}^{-} \rightarrow \mathrm{Ag}_{2} \mathrm{O}+\mathrm{H}_{2} \mathrm{O}+2 \mathrm{e}^{-}\right) \cdot{ }^{22}$ To eliminate these factors, we have added an additional experiment using $\mathrm{Hg} / \mathrm{HgO}$ electrode as the reference electrode. It shows a negligible degradation after long-term stability test (Figure S11), and is similar to that of the $\mathrm{Ag} / \mathrm{AgCl}$ electrode. 

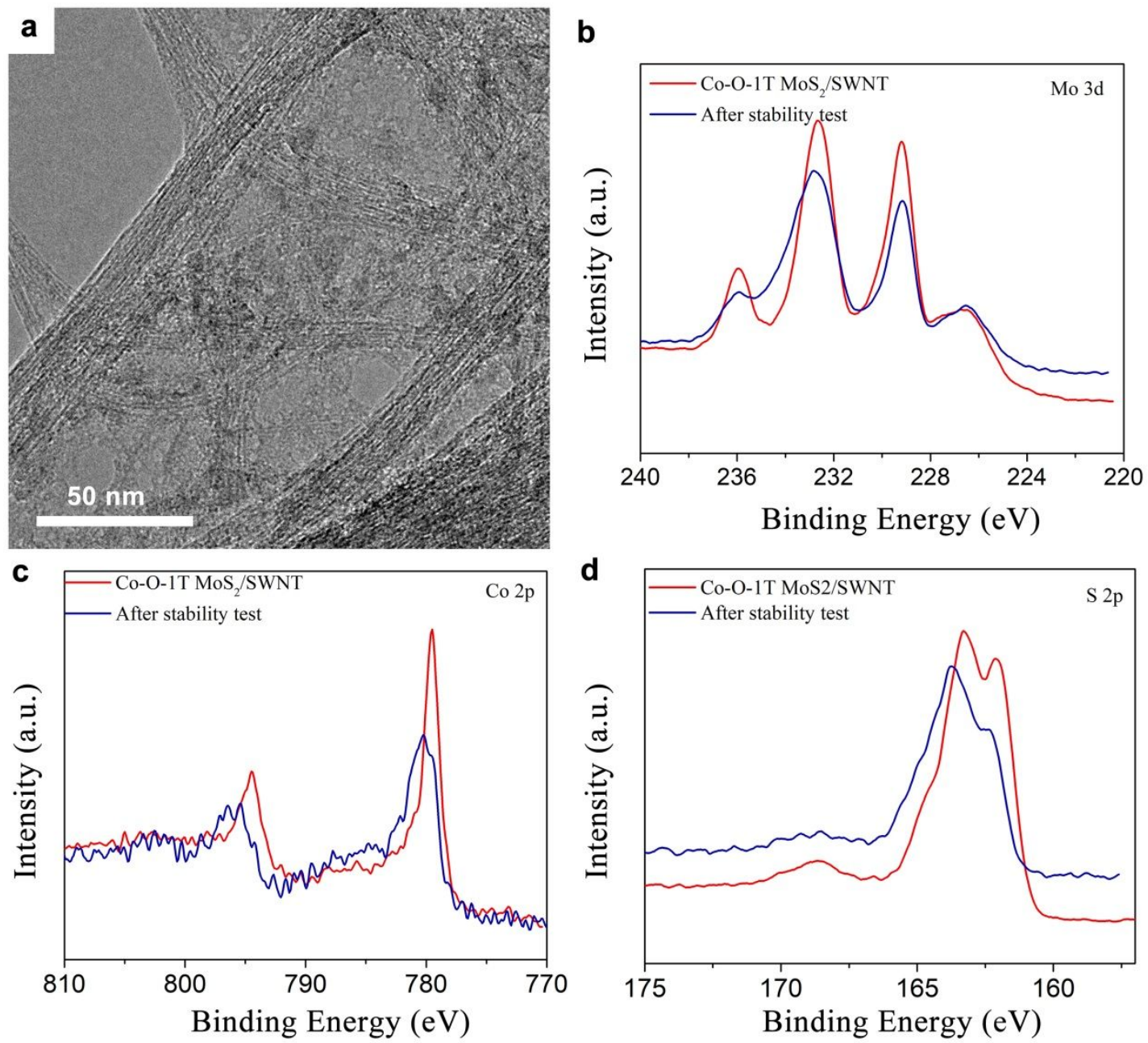

Figure S12. TEM and XPS spectra of the Co-O-1T-MoS $2 / \mathrm{SWNT}$ catalyst after stability test. 


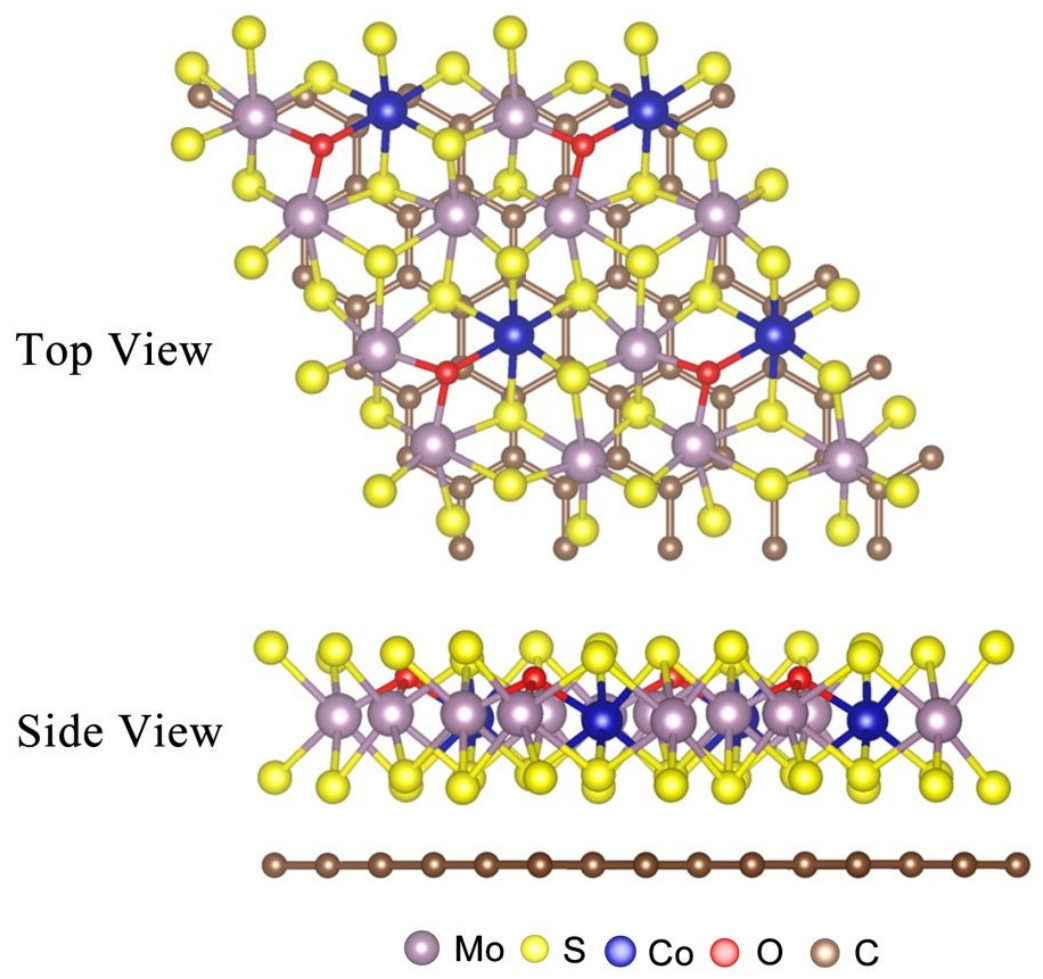

Figure S13. Top and side views of the optimized stable structure for Co-O-1T- $\mathrm{MoS}_{2} / \mathrm{SWNT}$ with a Mo/Co ratio of 3:1. 


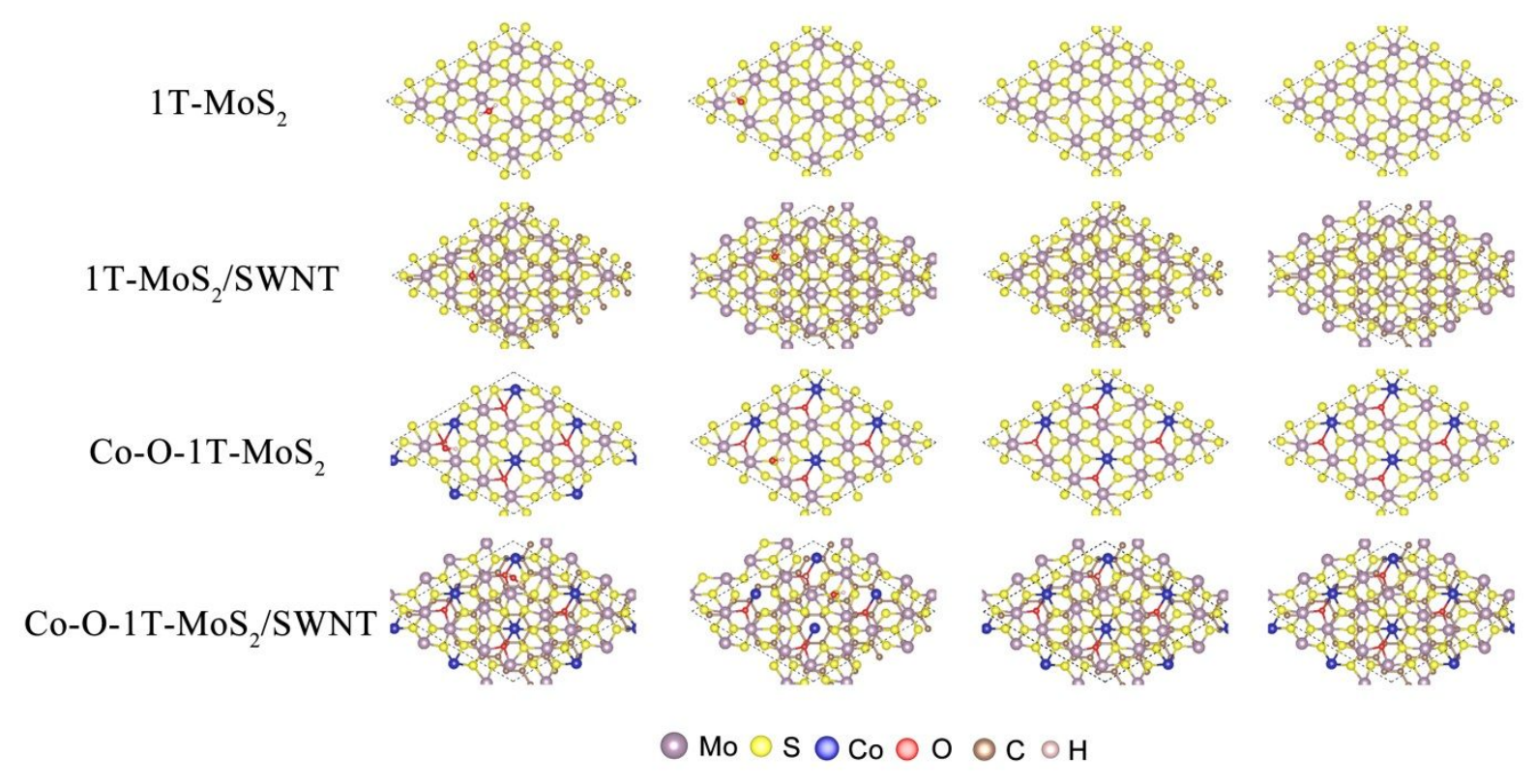

Figure S14. The most possible adsorption sites for the intermediate species on the surface of different catalyst models during alkaline HER. 
Table S1. The atomic percentage of $\mathrm{Mo}, \mathrm{Co}, \mathrm{S}, \mathrm{N}, \mathrm{O}$ and $\mathrm{C}$ for Co-O-1T- $\mathrm{MoS}_{2} / \mathrm{SWNT}$ obtained from XPS results.

\begin{tabular}{ccccccc}
\hline & $\begin{array}{c}\text { Mo } \\
(\text { at } \%)\end{array}$ & $\begin{array}{c}\text { Co } \\
(\text { at } \%)\end{array}$ & S (at\%) & N (at\%) & O (at\%) & C (at\%) \\
\hline $\begin{array}{c}\text { Co-O-1T-MoS } / \mathrm{S} \\
\text { WNT }\end{array}$ & 7.12 & 2.42 & 22.77 & 0.52 & 18.57 & 48.6 \\
\hline
\end{tabular}


Table S2. The fitting results of Co K-edge EXAFS spectra at $\mathrm{R}$ space for Co-O-1T- $\mathrm{MoS}_{2} / \mathrm{SWNT}$ and reference samples.

\begin{tabular}{ccccc}
\hline & Path & $\mathrm{N}$ & $\mathrm{R}(\AA)$ & $\sigma^{2}\left(10^{-3} \AA^{2}\right)$ \\
\cline { 2 - 5 } $\begin{array}{c}\mathrm{Co}-\mathrm{O}-1 \mathrm{~T}-\mathrm{M} \text { - } \\
\text { } / \mathrm{SWNT}\end{array}$ & $\mathrm{Co}-\mathrm{O}$ & 1.4 & 1.99 & 5.1 \\
& $\mathrm{Co}-\mathrm{S}$ & 4.2 & 2.27 & 7.8 \\
$\mathrm{c}-\mathrm{CoS}_{2}$ & $\mathrm{Co}-\mathrm{S}$ & 6 & 2.31 & 5.1 \\
$\mathrm{c}^{-\mathrm{Co}_{3} \mathrm{O}_{4}}$ & $\mathrm{Co}_{1}-\mathrm{O}$ & 2 & 1.94 & 2.1 \\
& $\mathrm{Co}_{2}-\mathrm{O}$ & 3 & 1.92 & 2.1 \\
\hline
\end{tabular}

Notes: $\mathrm{N}$ is coordination number, $\mathrm{R}$ is the bond length, and $\sigma^{2}$ is Debye-Waller factor. $\mathrm{Co}_{1}-\mathrm{O}$ and $\mathrm{Co}_{2}-\mathrm{O}$ represent the nearest and the next nearest $\mathrm{Co}-\mathrm{O}$ coordination in c- $-\mathrm{Co}_{3} \mathrm{O}_{4}$. 
Table S3. The ICP-AES result of the metal content of the Co-O-1T-MoS $2 / \mathrm{SWNT}$ catalyst loaded on the electrode.

\begin{tabular}{cccc}
\hline & Co & Mo & S \\
\hline $\begin{array}{c}\text { Co-O-1T-MoS } / \text { SWNT } \\
\left(\mu \mathrm{g} \mathrm{mL}^{-1}\right)\end{array}$ & 0.18 & 0.89 & 0.92 \\
\hline $\begin{array}{c}\text { Co-O-1T-MoS } / \text { SWNT } \\
\left(\mu \mathrm{mol} \mathrm{mL}^{-1}\right)\end{array}$ & 0.003 & 0.009 & 0.029 \\
\hline
\end{tabular}

Notes: The volume of the solution for ICP-AES test is $5 \mathrm{~mL}$. 
Table S4. The values of water dissociations and hydrogen generations on the surface of the energetic stable structures for different catalysts.

\begin{tabular}{ccc}
\hline & $\Delta \mathrm{G}\left(\mathrm{H}_{2} \mathrm{O}\right) / \mathrm{eV}$ & $\Delta \mathrm{G}\left(\mathrm{H}^{*}\right) / \mathrm{eV}$ \\
\hline $1 \mathrm{~T}-\mathrm{MoS}_{2}$ & 1.84 & 0.23 \\
1T- $\mathrm{MoS}_{2} / \mathrm{SWNT}$ & 1.63 & 0.24 \\
Co-O-1T-MoS & 0.94 & -0.24 \\
Co-O-1T-MoS $/$ SWNT & 0.79 & -0.23 \\
\hline
\end{tabular}




\section{References}

(1) Kresse, G.; Hafner. J. Ab. Initio Molecular Dynamics for Liquid Metals. Phys. Rev. $B$ 1993, 47, 558-561.

(2) Kresse, G.; Hafner, J. Ab Initio Molecular-Dynamics Simulation of the Liquid-Metal-Amorphous-Semiconductor Transition in Germanium. Phys. Rev. B 1994, 49, 14251-14269.

(3) Perdew, J. P.; Burke, K.; Ernzerhof, M. Generalized Gradient Approximation Made Simple. Phys. Rev. Lett. 1996, 77, 3865-3868.

(4) Dudarev, S.; Botton, G.; Savrasov, S.; Humphreys, C.; Sutton, A.

Electron-Energy-Loss Spectra and the Structural Stability of Nickel Oxide: An LSDA+U study. Phys. Rev. B 1998, 57, 1505-1509.

(5) Calderon, C. E.; Plata, J. J.; Toher, C.; Oses, C.; Levy, O.; Fornari, M.; Natan, A.; Mehl, M. J.; Hart, G.; Buongiorno Nardelli, M.; Curtarolo, S. The AFLOW Standard for High-Throughput Materials Science Calculations. Comput. Mater. Sci. 2015, 108, 233-238.

(6) Blöchl, P. E. Improved Tetrahedron Method Far Brilleuin-Zane Integratians. Phys. Rev. B 1994, 50, 16223-16233.

(7) Peterson, A. A.; Abild-Pedersen, F.; Studt, F.; Rossmeis1, J.; Nørskov, J. K. How Copper Catalyzes the Electroreduction of Carbon Dioxide into Hydrocarbon Fuels. Energy Environ. Sci. 2010, 3, 1311-1315.

(8) Lim, D.-H.; Wilcox, J. Mechanisms of the Oxygen Reduction Reaction on Defective Graphene-Supported Pt Nanoparticles from First-Principles. J. Phys.Chem. C 2012, 116, 3653-3660.

(9) Kattel, S.; Atanassov, P.; Kiefer, B. Density Functional Theory Study of Ni-N-x/C Electrocatalyst for Oxygen Reduction in Alkaline and Acidic Media. J. Phys.Chem. C 2012, 116, 17378-17383.

(10) Wang, Y.; Yuan, H.; Li, Y.; Chen, Z. Two-Dimensional Iron-Phthalocyanine (Fe-Pc) Monolayer as a Promising Single-Atom-Catalyst for Oxygen Reduction Reaction: a Computational Study. Nanoscale 2015, 7, 11633-11641. 
(11) Li, M.; Zhang, L.; Xu, Q.; Niu, J.; Xia, Z. N-doped Graphene as Catalysts for Oxygen Reduction and Oxygen Evolution Reactions: Theoretical Considerations. $J$. Catal. 2014, 314, 66-72.

(12) Nørskov, J. K.; Rossmeisl, J.; Logadottir, A.; Lindqvist, L.; Kitchin, J. R.; Bligaard, T.; J Ó nsson, H. Origin of the Overpotential for Oxygen Reduction at a Fuel-Cell Cathode. J. Phys.Chem. B 2004, 108, 17886-17892.

(13) Zhang, R.; Wang, X.; Yu, S.; Wen, T.; Zhu, X.; Yang, F.; Sun, X.; Wang, X.; $\mathrm{Hu}, \mathrm{W}$. Ternary $\mathrm{NiCo}_{2} \mathrm{Px}$ Nanowires as $\mathrm{pH}$-Universal Electrocatalysts for Highly Efficient Hydrogen Evolution Reaction. Adv. Mater. 2017, 29, 1605502.

(14) Li, L.; Qin, Z.; Ries, L.; Hong, S.; Michel, T.; Yang, J.; Salameh, C.; Bechelany, M.; Miele, P.; Kaplan, D.; Chhowalla, M.; Voiry, D. Role of Sulfur Vacancies and Undercoordinated Mo Regions in $\mathrm{MoS}_{2}$ Nanosheets toward the Evolution of Hydrogen. ACS Nano 2019, 13, 6824-6834.

(15) Lv, Z.; Tahir, M.; Lang, X.; Yuan, G.; Pan, L.; Zhang, X.; Zou, J.-J. Well-Dispersed Molybdenum Nitrides on a Nitrogen-Doped Carbon Matrix for Highly Efficient Hydrogen Evolution in Alkaline Media. J. Mater. Chem. A 2017, 5, 20932-20937.

(16) Xiao, X.; Huang, D.; Fu, Y.; Wen, M.; Jiang, X.; Lv, X.; Li, M.; Gao, L.; Liu, S.; Wang, M.; Zhao, C.; Shen, Y. Engineering NiS/Ni ${ }_{2} \mathrm{P}$ Heterostructures for Efficient Electrocatalytic Water Splitting. ACS Appl. Mater. Interfaces 2018, 10, 4689-4696.

(17) Hu, J.; Zhang, C.; Jiang, L.; Lin, H.; An, Y.; Zhou, D.; Leung, M. K. H.; Yang, S. Nanohybridization of $\mathrm{MoS}_{2}$ with Layered Double Hydroxides Efficiently Synergizes the Hydrogen Evolution in Alkaline Media. Joule 2017, 1, 383-393.

(18) Huang, Y.; Sun, Y.; Zheng, X.; Aoki, T.; Pattengale, B.; Huang, J.; He, X.; Bian, W.; Younan, S.; Williams, N,; Hu, J.; Ge, J.; Pu, N.; Yan, X.; Pan, X.; Zhang, L.; Wei, Y.; Gu, J. Atomically Engineering Activation Sites onto Metallic 1T- $\mathrm{MoS}_{2}$ Catalysts for Enhanced Electrochemical Hydrogen Evolution. Nat. Commun 2019, 10, 982.

(19) Zhang, J.; Wang, T.; Liu, P.; Liu, S.; Dong, R.; Zhuang, X.; Chen, M.; Feng, X. Engineering Water Dissociation Sites in $\mathrm{MoS}_{2}$ Nanosheets for Accelerated 
Electrocatalytic Hydrogen Production. Energy Environ. Sci. 2016, 9, 2789-2793.

(20) Kou, Z.; Wang, T.; Wu, H.; Zheng, L.; Mu, S.; Pan, Z.; Lyu, Z.; Zang, W.; Pennycook, S. J.; Wang, J. Twinned Tungsten Carbonitride Nanocrystals Boost Hydrogen Evolution Activity and Stability. Small 2019, 15, 1900248.

(21) Choi, Y.-H.; Lee, J.; Parija, A.; Cho, J.; Verkhoturov, S. V.; Al-Hashimi, M.; Fang, L.; Banerjee, S. An In Situ Sulfidation Approach for the Integration of $\mathrm{MoS}_{2}$ Nanosheets on Carbon Fiber Paper and the Modulation of Its Electrocatalytic Activity by Interfacing with $\mathrm{nC}_{60}$. ACS Catal. 2016, 6, 6246-6254.

(22) Stevens, M. B.; Enman, L. J.; Batchellor, A. S.; Cosby, M. R.; Vise, A. E.; Trang, C. D. M.; Boettcher, S. W. Measurement Techniques for the Study of Thin Film Heterogeneous Water Oxidation Electrocatalysts. Chem. Mater. 2017, 29, $120-140$. 